\title{
Use of Stone Powder Sludge in Fly Ash-Based Geopolymer
}

\author{
Se-Jin Choi \\ Ph.D, R\&D Center, SAMPYO Corporation. Seoul, Korea
}

\begin{abstract}
Stone powder sludge is a by-product of the manufacturing process of crushed sand. Most of it is dumped with soil in landfills, and the disposal of stone powder sludge causes a major environmental problem. This paper investigates the applicability of stone powder sludge in fly ashbased geopolymer. For this, stone powder sludge was used to replace fly ash at a replacement ratio of $50 \%$ and $100 \%$ by weight. The compressive strength of the samples was measured and scanning electron microscopy/ energy dispersive spectroscopy (SEM/EDS) analysis and X-ray diffraction (XRD) were performed. The test results indicated that the optimum level of the alkali activator ratio $\left(\mathrm{Na}_{2} \mathrm{SiO} / \mathrm{NaOH}_{3}\right.$ for fly ash-based geopolymer using stone powder sludge was 1.5. The strength development is closely related to the NaOH solution concentration. In addition, the compressive strength of the sample cured at $25^{\circ} \mathrm{C}$ was significantly improved between 7 days and 28 days, even though the strength of the sample showed the lowest value at 7 days. Microscopy results indicated that a higher proportion of unreacted fly ash spheres remained in the sample with $5 \mathrm{M} \mathrm{NaOH}$, and some pores on the surface of the sample were observed.
\end{abstract}

Keywords : Stone Powder Sludge, Fly Ash, Geopolymer, Alkali Activator, Compressive Strength

\section{INTRODUCTION}

Stone powder sludge is a by-product of the manufacturing process of crushed sand. It is collected by a filter press from the washed sludge water where water is used to clean the powder of crushed sand.

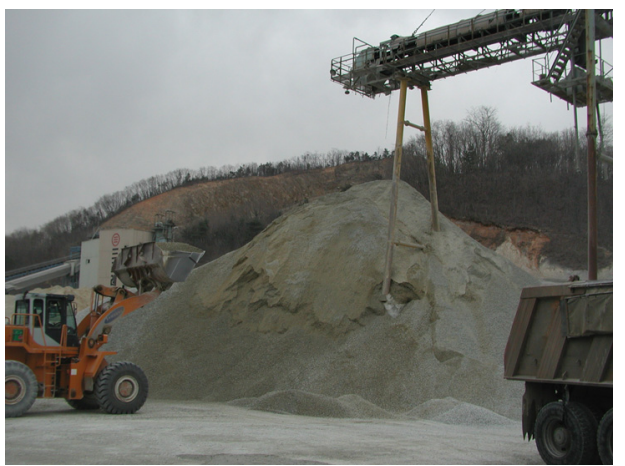

(a) Manufacture of crushed sand

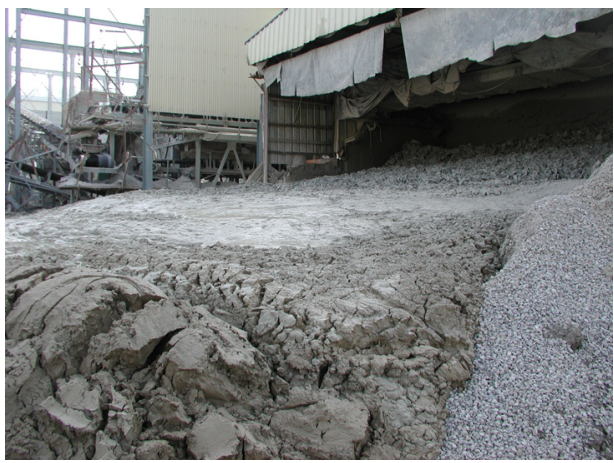

(b) Stone powder sludge

Figure 1. Manufacture of crushed sand and stone powder sludge

In Korea, the usage rate of crushed sand for concrete has been increasing due to the exhaustion of good natural aggregates such as river sand. Recently, the usage rate of crushed sand for concrete was about $32 \%$ in Korea (Choi et al., 2006). Therefore, the quantity of stone powder sludge from crushed aggregate factories has been increasing every year, and it is approximately 7.5 million tons each year. Fig. 1 presents crushed aggregate factory and stone powder sludge produced by manufacturing crushed sand. The water content in stone powder sludge ranges from $20 \%$ to $40 \%$ by weight, and due to this it is difficult to handle, transport and recycle stone powder sludge. Therefore, most stone powder sludge is dumped with soil in landfills or abandoned on factory sites. The disposal of stone powder sludge causes a major environmental problem. Hence, there is great need to investigate solutions on how to utilize a by-product such as stone powder sludge in concrete industry more efficiently. An earlier study (Kim et al., 2006) reported that stone powder sludge usually consists of $\mathrm{SiO}_{2}$ and $\mathrm{Al}_{2} \mathrm{O}_{3}$, that is, the compositions of stone powder sludge is similar to Class F fly ash. It is well known that Class F fly ash can be used in Geopolymer as a raw material (Duxson et al., 2007; Fernández-Jiménez et al., 2007). The reaction of solid aluminosilicate with a highly concentrated aqueous alkali hydroxide or silicate solution can produce a synthetic alkali aluminosilicate material generically called 'geopolymer'(Davidovits, 1989). Davidovits (1988) introduced the term 'geopolymer' in 1978 to represent the mineral polymers resulting from geochemistry. The chemical composition of geopolymer materials is similar to zeolite, but they reveal an amorphous microstructure (Davidovits, 1999). This material can provide performance comparable to traditional cementitious binders in a range of applications, but with the added advantage of significantly reduced greenhouse gas emissions because cement manufacture generates carbon dioxide $\left(\mathrm{CO}_{2}\right)$ emissions from calcinations of limestone in the raw materials, and from fuel combustion at the rate of approximately 1 ton of $\mathrm{CO}_{2}$ per ton of cement (Gartner, 2004; Carroll et al., 1998; Xu, 1997). Geopolymer can be made from industrial waste materials such as 
fly ash and granulated blast furnace slag, which can provide a replacement for the silicates concentrations required for matrix formation of geopolymer (Sofi et al., 2007). It might be expected that the stone powder sludge could be used in geopolymer as a raw material because of the similar compositions of stone powder sludge to Class $\mathrm{F}$ fly ash. During the last few years, some researchers have studied the use of stone powder sludge in the cement and concrete industries (Takayuki and Masaru, 2002; Han et al., 2001). However, in their studies, they used stone powder mainly as filler in cement mortar or concrete.

In this paper, the strength development and microstructure of fly ash-based geopolymer using stone powder sludge has been studied. The objective of this investigation is to compare and analyze the strength, SEM/EDS and Xray diffraction analysis of fly ash-based Geopolymer using stone powder sludge, with the ultimate goal of using stone powder sludge in concrete industry more efficiently.

\section{EXPERIMENTAL PROCEDURE}

(1) Materials

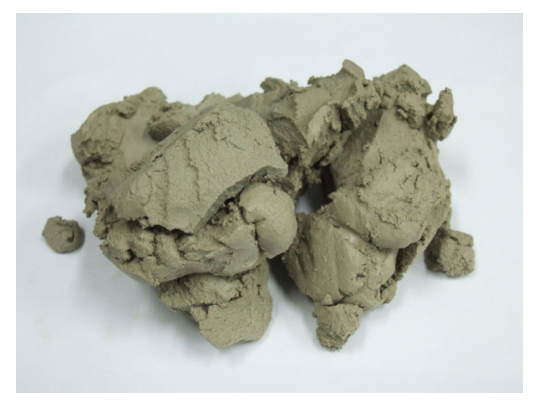

Figure 2. Stone powder sludge

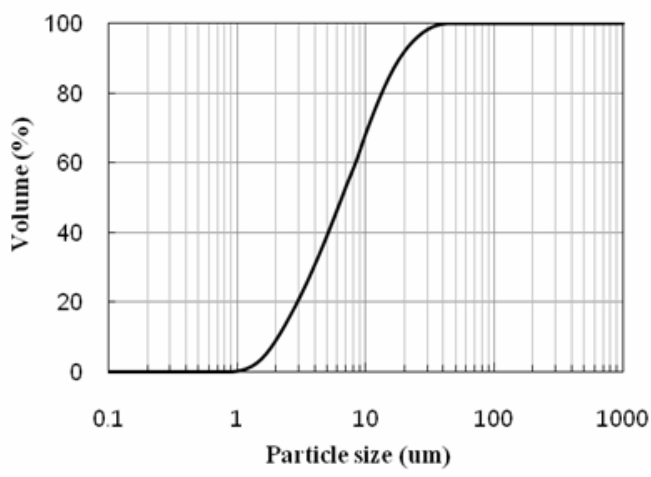

Figure 3. Grading curve of stone powder sludge

The particle size of the stone powder sludge ranged from 0.92 to $46.08 \mu \mathrm{m}$, and the average size of the particle was about $7 \mu \mathrm{m}$. Fig. 3 shows the grading curve of stone powder sludge for this study. Fig. 4 and 5 show the scanning electron microscope (SEM) image and X-ray diffraction (XRD) patterns of stone powder sludge, respectively. SEM and XRD analysis indicated that the stone powder sludge consisted mainly of a glassy phase, quartz, muscovite and albite. The densities of fly ash and stone powder sludge were 2.25 and 1.95 , respectively.

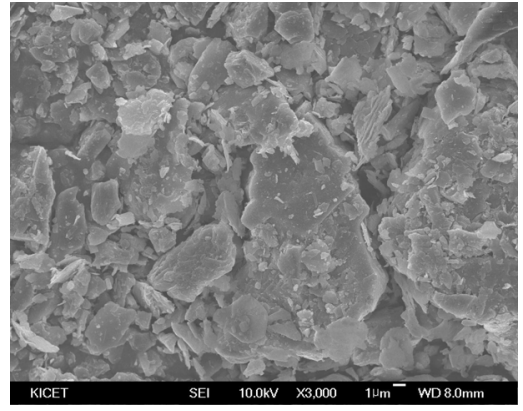

Figure 4. SEM image of stone powder sludge

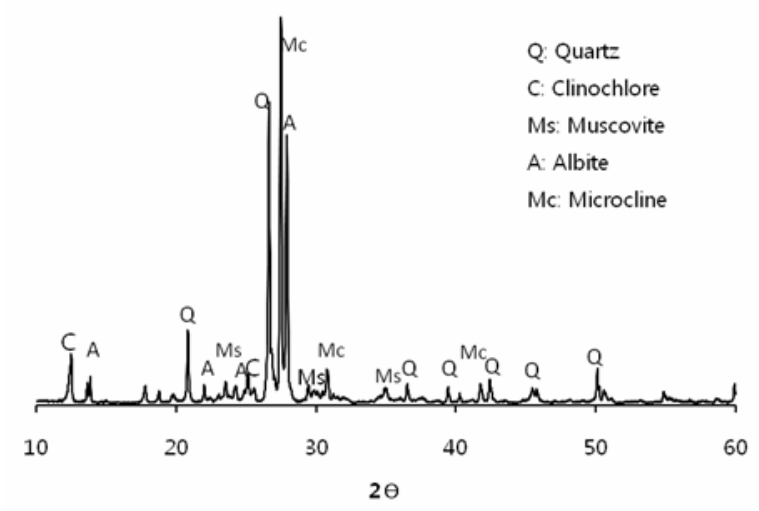

Figure 5. XRD patterns of stone powder sludge

Table 1. Chemical composition of fly ash and stone powder sludge

\begin{tabular}{lccccccc}
\hline Materials & $\mathrm{SiO}_{2}$ & $\mathrm{Al}_{2} \mathrm{O}_{3}$ & $\mathrm{Fe}_{2} \mathrm{O}_{3}$ & $\mathrm{~K}_{2} \mathrm{O}$ & $\mathrm{CaO}$ & $\mathrm{MgO}$ & $\mathrm{Na}_{2} \mathrm{O}$ \\
\hline Fly ash & 56.07 & 27.18 & 5.48 & 1.25 & 3.46 & 0.01 & 0.05 \\
Sludge & 62.11 & 15.72 & 4.08 & 4.98 & 3.02 & 2.25 & 2.64 \\
\hline
\end{tabular}

Table 2. Mixture proportions of samples

\begin{tabular}{|c|c|c|c|c|c|c|c|}
\hline Step & $\begin{array}{c}\text { Mix } \\
\text { no }\end{array}$ & $\begin{array}{c}\text { Sludge } \\
(\%)\end{array}$ & $\begin{array}{l}\text { Fly } \\
\text { ash } \\
(\%)\end{array}$ & $\begin{array}{l}\text { Act/ } \\
(\mathrm{FS})^{*}\end{array}$ & $\begin{array}{l}\mathrm{NaOH} \\
\text { (mole) }\end{array}$ & $\begin{array}{c}\mathrm{Na}_{2} \mathrm{SiO}_{3} / \\
\mathrm{NaOH}\end{array}$ & Curing conditions \\
\hline \multirow[t]{3}{*}{ I } & 1 & 100 & 0 & 0.2 & $10 \mathrm{M}$ & 0.5 & $80^{\circ} \mathrm{C}(24 \mathrm{hr})+$. room \\
\hline & 2 & & & 0.2 & $10 \mathrm{M}$ & 1.5 & $80^{\circ} \mathrm{C}(24 \mathrm{hr})+$. room \\
\hline & 3 & & & 0.2 & $10 \mathrm{M}$ & 2.5 & $80^{\circ} \mathrm{C}(24 \mathrm{hr})+$. room \\
\hline \multirow[t]{7}{*}{ II } & 4 & 50 & 50 & 0.3 & $10 \mathrm{M}$ & 0.5 & $80^{\circ} \mathrm{C}(24 \mathrm{hr})+$. room \\
\hline & 5 & & & 0.3 & $10 \mathrm{M}$ & 1.0 & $80^{\circ} \mathrm{C}(24 \mathrm{hr})+$. room \\
\hline & 6 & & & 0.3 & $5 \mathrm{M}$ & 1.5 & $80^{\circ} \mathrm{C}(24 \mathrm{hr})+$. room \\
\hline & 7 & & & 0.3 & $10 \mathrm{M}$ & 1.5 & $80^{\circ} \mathrm{C}(24 \mathrm{hr})+$. room \\
\hline & 8 & & & 0.3 & $15 \mathrm{M}$ & 1.5 & $80^{\circ} \mathrm{C}(24 \mathrm{hr})+$. room \\
\hline & 9 & & & 0.3 & $10 \mathrm{M}$ & 1.5 & $25^{\circ} \mathrm{C}$ (constant) \\
\hline & 10 & & & 0.3 & $10 \mathrm{M}$ & 1.5 & $80^{\circ} \mathrm{C}$ (constant) \\
\hline
\end{tabular}

*Activator/(Fly ash + stone powder sludge)

Class F fly ash obtained from the thermal power plant at Dangjin in Korea was used. The stone powder sludge used in this investigation was granite sludge that had a water content of $20.7 \%$ by weight, from S. Aggregate (Fig. 2). 
The chemical compositions of fly ash and stone powder sludge are shown in Table 1. For alkali activation of the paste, after referring to previous reports (FernándezJiménez et al., 1999; Wang et al., 1994); a sodium silicate solution $\left(\mathrm{Na}_{2} \mathrm{SiO}_{3}\right)$ and sodium hydroxide solution $(\mathrm{NaOH})$ were used. The sodium silicate solution with a $1.36 \mathrm{~g} / \mathrm{cm}^{3}$ density with $\mathrm{Ms}=3.12\left(\mathrm{Na}_{2} \mathrm{O}=8.2 \%\right.$ and $\left.\mathrm{SiO}_{2}=26.4 \%\right)$ was supplied by PQ USA. The sodium hydroxide solution was supplied by Fisher Scientific USA.

\section{(2) Methods}

Stone powder sludge was used to replace fly ash at replacement ratio of $50 \%$ and $100 \%$ by weight. The activator solution to FS(fly ash + stone powder sludge) ratio of the samples was 0.2 (step I ) and 0.3 (step II). The variables considered in this investigation were:

- Activator solution ratio $\left(\mathrm{Na}_{2} \mathrm{SiO}_{3} / \mathrm{NaOH}\right): 0.5-2.5$

- $\mathrm{NaOH}$ solution concentration: $5 \mathrm{M}, 10 \mathrm{M}$ and $15 \mathrm{M}$

- Curing conditions: $80^{\circ} \mathrm{C}(24$ hours $)+$ room, $25^{\circ} \mathrm{C}$ (constant) and $80^{\circ} \mathrm{C}$ (constant)

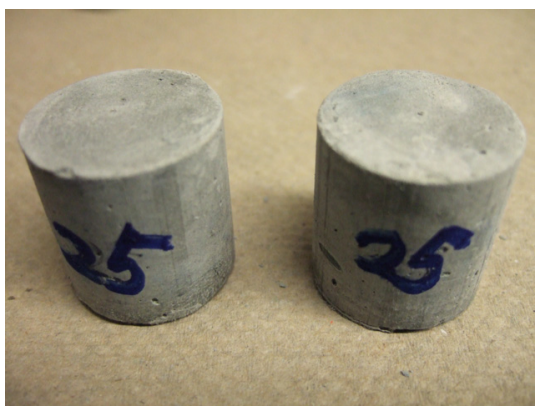

Figure 6. Samples of fly ash-based geopolymer with stone powder sludge

Table 3. Compressive strength test results

\begin{tabular}{cccccc|c}
\hline \multirow{2}{*}{ Step } & $\begin{array}{c}\text { Mix } \\
\text { no }\end{array}$ & $\begin{array}{c}\text { Sludge } \\
(\%)\end{array}$ & $\begin{array}{c}\mathrm{NaOH} \\
(\mathrm{mole})\end{array}$ & $\begin{array}{c}\mathrm{Na}_{2} \mathrm{SiO}_{3} / \\
\mathrm{NaOH}\end{array}$ & \multicolumn{2}{c}{ Strength (MPa) } \\
\cline { 6 - 7 } $\mathrm{I}$ & 1 & 100 & $10 \mathrm{M}$ & 0.5 & 1.05 & - \\
& 2 & & $10 \mathrm{M}$ & 1.5 & 1.32 & - \\
& 3 & & $10 \mathrm{M}$ & 2.5 & 0.57 & - \\
\hline II & 4 & 50 & $10 \mathrm{M}$ & 0.5 & 3.29 & - \\
& 5 & & $10 \mathrm{M}$ & 1.0 & 3.42 & - \\
& 6 & & $5 \mathrm{M}$ & 1.5 & 0.97 & 1.80 \\
& 7 & & $10 \mathrm{M}$ & 1.5 & 4.99 & 8.46 \\
& 8 & & $15 \mathrm{M}$ & 1.5 & 5.79 & 11.96 \\
& 9 & & $10 \mathrm{M}$ & 1.5 & 2.63 & 19.29 \\
& 10 & & $10 \mathrm{M}$ & 1.5 & 5.00 & 10.35 \\
\hline
\end{tabular}

The mix proportions of this study are given in Table 2 .

Fly ash and stone powder sludge were mixed with the alkaline solution and then cast into $\phi 25.4 \mathrm{~mm} \times 25.4 \mathrm{~mm}$ cylinder shaped moulds. Fig. 6 shows the samples of the fly ash-based geopolymer paste with stone powder sludge. All specimens except the samples tested for curing conditions were cured at $80^{\circ} \mathrm{C}$ for 24 hours in a chamber. They were then kept at a room temperature of about $23^{\circ} \mathrm{C}$ until the strength test. The samples for the curing condition test were cured at $25^{\circ} \mathrm{C}$ and $80^{\circ} \mathrm{C}$ constantly.

The compressive strength was measured with a Baldwin Universal testing machine at the University of California, Berkeley. For micro structurally observation, some samples were studied by LEO 430 scanning electron microscope/energy dispersive spectroscopy (SEM/EDS) and Xray diffraction (XRD). The SEM/EDS analysis utilized secondary electron imaging of a cross section of test samples, which were dried and coated with a thin film of gold before undergoing SEM. X-ray powder diffraction patterns were obtained using a PANalytical X'Pert PRO MPD diffractometer with $\operatorname{CoK} \alpha(\lambda=1.790 \AA)$ radiation. For this, some samples were finely ground to powder.

\section{RESULTS AND DISCUSSION}

(1) Mechanical strength

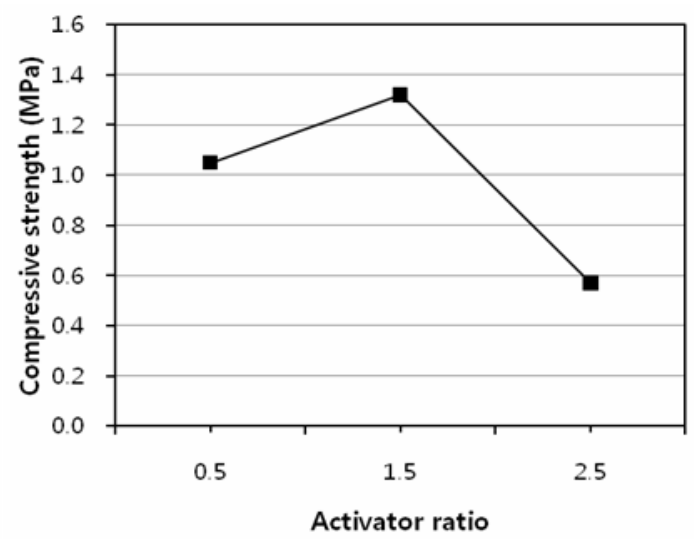

Figure 7. Compressive strength versus activator ratio (Stone powder sludge 100\%, 7 days)

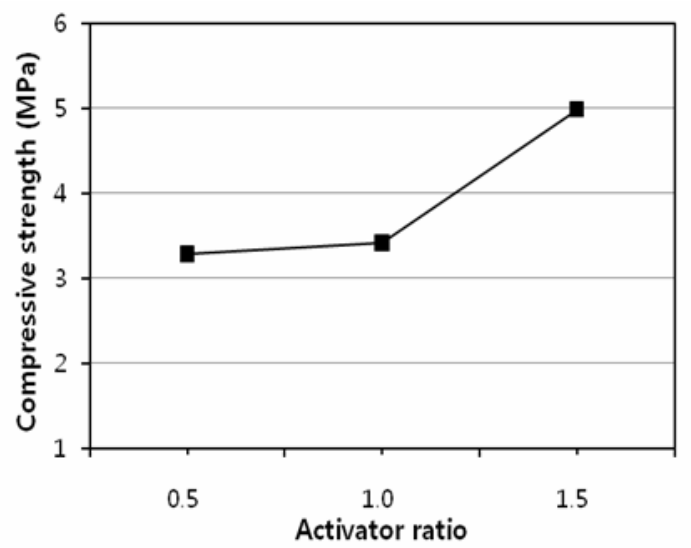

Figure 8. Compressive strength of fly ash-based Geopolymer with stone powder sludge versus activator ratio (7 days)

The test results for the compressive strength are given in Table 3 and shown in Fig. 7, which shows the variation of compressive strength of the samples using $100 \%$ stone powder sludge with an alkali activator ratio $\left(\mathrm{Na}_{2} \mathrm{SiO}_{3} /\right.$ $\mathrm{NaOH}$ ). The test results reveal that the compressive strength of the sample with a 1.5 alkali activator ratio shows the highest strength, and the compressive strength 
of the sample with a 2.5 alkali activator ratio shows the lowest strength. This trend is different from that of the fly ash-based binder investigated in the previous work (Kong et al., 2006). The previous study reported that the compressive strength of fly ash-based binders with ratios ranging from 1.5 to 2.5 presented relatively higher strength. However, the compressive strength of the all samples using $100 \%$ stone powder sludge was very low $(0.5-1.3 \mathrm{MPa})$. This low strength of the samples may be because the alkali-activation level of the stone powder sludge samples without fly ash was low. This means that when making alkali-activated paste with only stone powder sludge, it is hard to achieve a high-strength paste. Table 3 and Figs 8, 9 and 10 show the variations of compressive strength of the fly ash-based Geopolymer samples with $50 \%$ stone powder sludge by alkali activator ratio, $\mathrm{NaOH}$ concentration and curing conditions. From Fig. 8, it can be seen that the strength trend of the samples is similar to that in Fig. 7, the strength of the sample with a 1.5 alkali activator ratio was the highest value. Therefore, according to this investigation, the optimum level of alkali activator ratio for fly ashbased Geopolymer using stone powder sludge is 1.5.

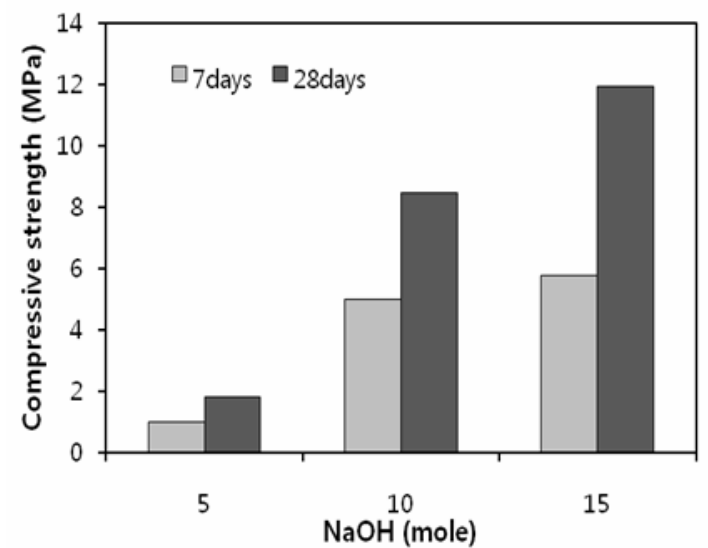

Figure 9. Compressive strength of fly ash-based Geopolymer with stone powder sludge versus $\mathrm{NaOH}$ concentration

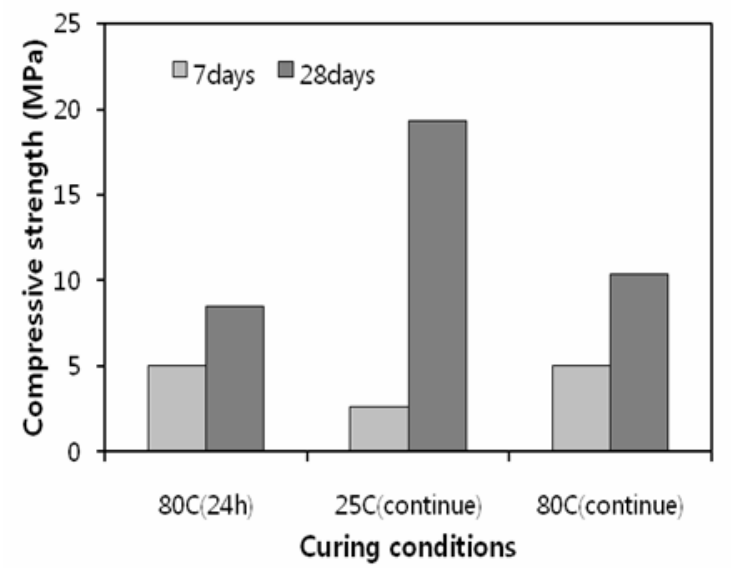

Figure 10. Compressive strength of fly ash-based Geopolymer with stone powder sludge versus curing conditions

From earlier study (Kong et al., 2006), it is reported that there was a noticeable improvement in strength with increasing activator ratio (0.5-2.5). The compressive strength of the samples with activator ratios ranged from 3.29 to $4.99 \mathrm{MPa}$ at 7days.

With a 1.5 fixed alkali activator ratio, Fig. 9 presents the compressive strength of the samples using stone powder sludge with $\mathrm{NaOH}$ solution concentration. The test results show that the strength development is closely related to the $\mathrm{NaOH}$ solution concentration. The compressive strength of the samples increased as the $\mathrm{NaOH}$ solution concentration increased at all ages. For the sample with $5 \mathrm{M} \mathrm{NaOH}$, the compressive strength was very low, about $1 \mathrm{MPa}$ at 7 days. And even at 28 days, the compressive strength of the sample was about $1.8 \mathrm{MPa}$. However, when the $\mathrm{NaOH}$ solution concentration was over $10 \mathrm{M}$, the compressive strength of the samples improved significantly.

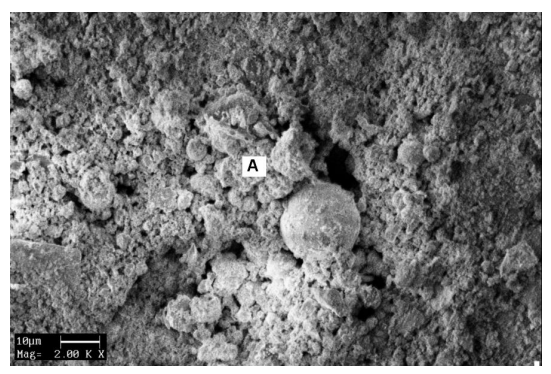

(a) $\mathrm{NaOH} 5 \mathrm{M}$

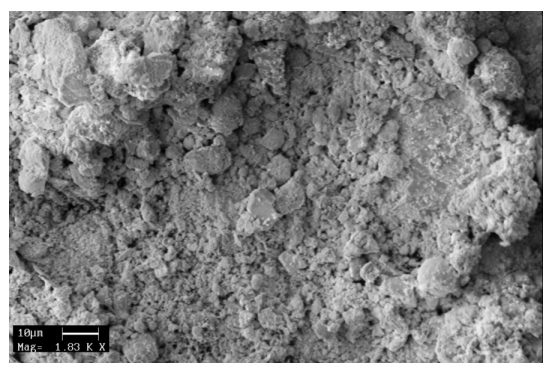

(b) $\mathrm{NaOH} 10 \mathrm{M}$

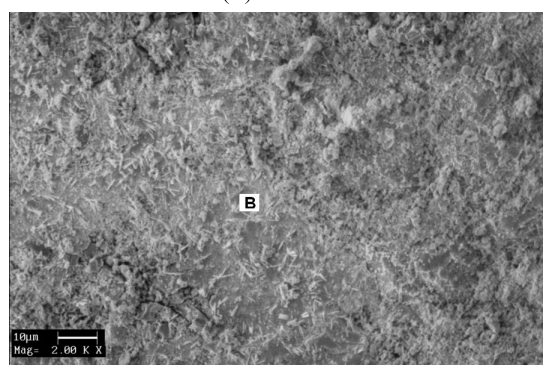

(c) $\mathrm{NaOH} 15 \mathrm{M}$

Figure 11. SEM micrographs of samples versus $\mathrm{NaOH}$ concentrations (7 days)

Alonso and Palomo (2001) described that a great difference between the activation reaction carried out with $\mathrm{NaOH} 5 \mathrm{M}$ and those carried out with the other solution concentrations $(10,12,15$, and $18 \mathrm{M})$ could be observed. When $[\mathrm{NaOH}] \geq 10 \mathrm{M}$, curve profiles, which corresponds to the massive precipitation of reaction products were very similar. On the contrary, the calorimetric signal corresponding to activation with $5 \mathrm{M} \mathrm{NaOH}$ was sensibly lower 
in the paper.

The compressive strength of the samples with $10 \mathrm{M}$ and $15 \mathrm{M} \mathrm{NaOH}$ was about 5 to 6 times larger than that of the sample with $5 \mathrm{M} \mathrm{NaOH}$ at 7 days, and it continued to increase as the age increased. As it can be observed in the figure, the compressive strength of the sample activated with $15 \mathrm{M} \mathrm{NaOH}$ was greater than those of the samples activated with $5 \mathrm{M}$ and $10 \mathrm{M} \mathrm{NaOH}$. It was about $12 \mathrm{MPa}$ at 28 days. Fig. 10 shows the variation of compressive strength of the samples with curing conditions of 3 levels $\left(80^{\circ} \mathrm{C}\right.$ for 24 hours, constant state of $25^{\circ} \mathrm{C}$ and $80^{\circ} \mathrm{C}$ ) at a fixed alkali activator ratio of 1.5 and $10 \mathrm{M} \mathrm{NaOH}$. The compressive strength of the sample cured at $80^{\circ} \mathrm{C}$ for 24 hours presented a similar trend to that of the sample cured at $80^{\circ} \mathrm{C}$ continuously. This means that curing at $80^{\circ} \mathrm{C}$ for 24 hours may be better than curing at $80^{\circ} \mathrm{C}$ continuously in terms of cost. The compressive strength of the sample cured at $25^{\circ} \mathrm{C}$ continuously was significantly improved between 7 days and 28 days, even though the compressive strength of the sample was lower than any other mixes at 7 days. It was 19.2 MPa at 28 days. This may be because the geopolymerization occurred slowly at room temperature and it made fewer reaction products and had a lower compressive strength at the early ages. But this reaction continued to occur and it made a higher compressive strength at 28 days. With the samples cured at $80^{\circ} \mathrm{C}$, the early age reaction was active and the strength was relatively high, but continuous reaction may not occur a lot.

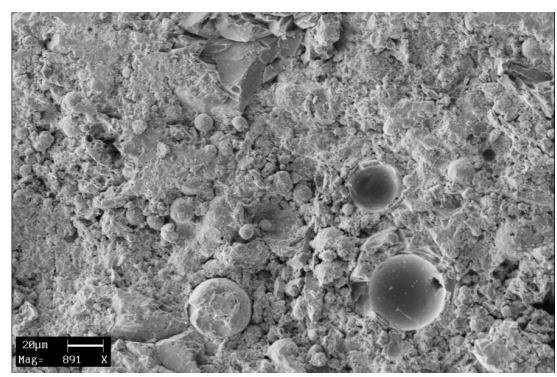

(a) $25^{\circ} \mathrm{C}$

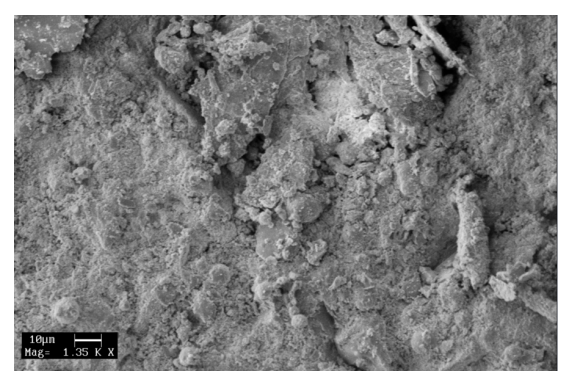

(b) $80^{\circ} \mathrm{C}$

Figure 12. SEM micrographs of samples versus curing conditions (7 days)

A previous investigation (Fernández-Jiménez et al., 1999) also observed that the strength of alkali-activated slag mortars decreased as the curing temperature increased. They concluded that at early ages the temperature effect is positive. However, as reaction time increased, the positive effect of the curing temperature disappeared, turning into a negative effect.

\section{(2) SEM/EDS analysis}

The microstructures and the semi-quantitative compositions of some samples were studied using a scanning electron microscope (SEM) with energy dispersive spectroscopy (EDS). The test results are shown in Figs 11, 12 and 13. Figs 11 and 12 show the SEM micrographs of a cross section of the samples. As it can be observed Fig. 11, which shows the SEM images of the fly ash-based geopolymer samples with stone powder sludge by $\mathrm{NaOH}$ solution concentration, a higher proportion of the unreacted fly ash spheres remain in the sample with a low $\mathrm{NaOH}$ concentration (5M). In addition, some pores on the surface of the $5 \mathrm{M} \mathrm{NaOH}$ sample are observed. This may be due to the fewer geopolymerization reactions at a low $\mathrm{NaOH}$ concentration, which might cause low strength development of the sample. Fig. 13 shows the EDS analysis of the products in the samples with $5 \mathrm{M}$ and $15 \mathrm{M} \mathrm{NaOH}$. The results of EDS analysis of area A in Fig. 11 show that it was mainly alumina-silicates with a small amount of $\mathrm{Na}$ component, typical of fly ash and stone powder sludge particles. However, the matrix of area B in Fig. 11 is composed of $\mathrm{Na}, \mathrm{Al}$ and $\mathrm{Si}$ components characteristics of a geopolymer resin. This means that a more active reaction occurred in $15 \mathrm{M} \mathrm{NaOH}$ concentration. For the curing temperature effect, comparison of the micrographs of $25^{\circ} \mathrm{C}$ and $80^{\circ} \mathrm{C}$ samples show that the number of unreacted fly ash particles in the $25^{\circ} \mathrm{C}$ sample matrix is larger than that in the $80^{\circ} \mathrm{C}$ sample matrix. This may be due to the relatively slow alkali-activation of the $25^{\circ} \mathrm{C}$ sample at room temperature condition.

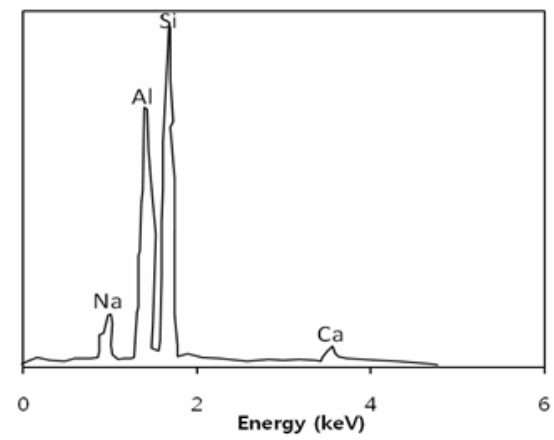

(a) Area A

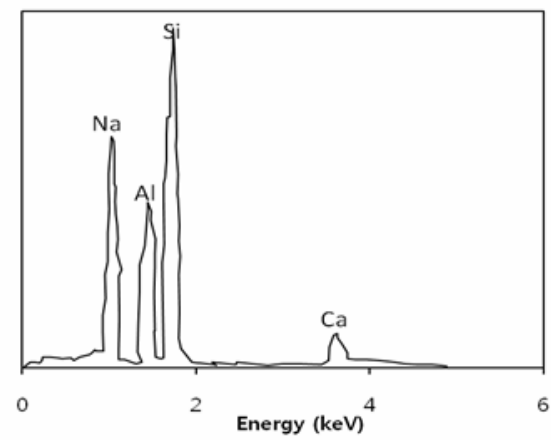

(b) Area B

Figure 13. Composition of (a) area A and (b) area B in Fig. 11, analyzed by EDS 
(3) X-ray diffraction

The test results are given in Fig. 14, which presents the XRD patterns of the fly ash-based geopolymer samples with stone powder sludge by $\mathrm{NaOH}$ concentrations, indicating the identified phases. For the XRD diagrams, the broad and diffuse peaks are shown around $2 \theta=35^{\circ}$, implying amorphous short-ordering structure phases generally emerged in the geopolymer. The sample that was obtained when the fly ash and stone powder sludge were activated with solutions of alkali hydroxide mixed with sodium silicate does not contain any crystalline phase except the ones existing in the fly ash and stone powder sludge such as quartz, mullite, muscovite, hematite and albite.

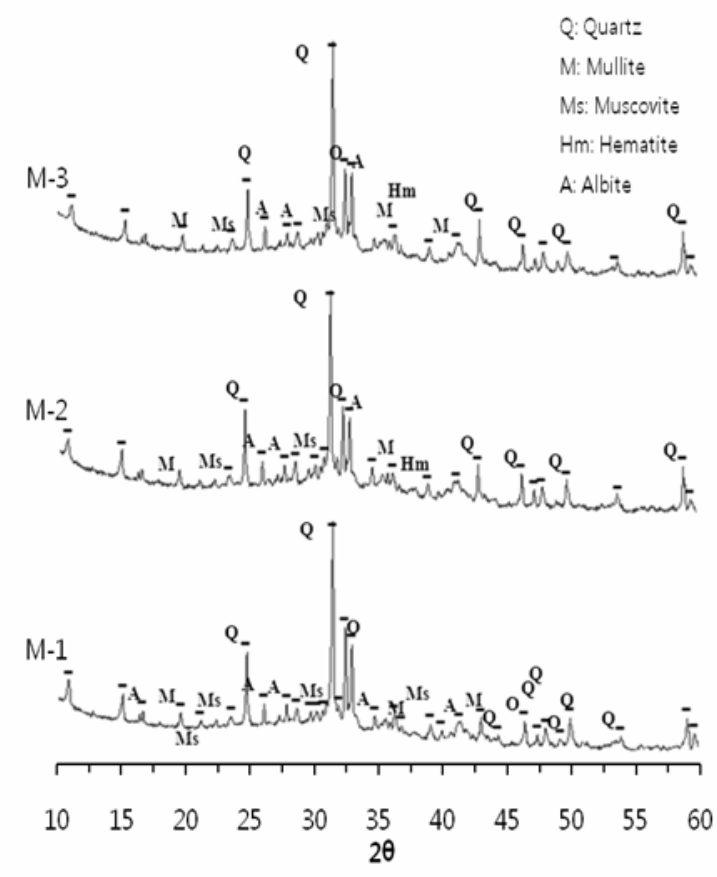

Figure 14. XRD patterns of M-1(5M), M-2(10M) and $\mathrm{M}-3(15 \mathrm{M})$ samples

For the sample with $5 \mathrm{M} \mathrm{NaOH}$, muscovite of the stone powder sludge was observed. However, it was not observed in the samples with $10 \mathrm{M}$ and $15 \mathrm{M} \mathrm{NaOH}$. In addition, albite can be seen more in the sample with $5 \mathrm{M} \mathrm{NaOH}$. This may mean that for high $\mathrm{NaOH}$ solution concentration, some part of the stone powder sludge was reacted with the alkali activator.

\section{CONCLUSIONS}

The following conclusions were obtained, based on the present investigation.

(1) In this investigation, the optimum alkali activator ratio $\left(\mathrm{Na}_{2} \mathrm{SiO}_{3} / \mathrm{NaOH}\right)$ for fly ash-based Geopolymer using stone powder sludge is 1.5 .

(2) The strength development is closely related to the $\mathrm{NaOH}$ solution concentration. The compressive strength of the samples increased as the $\mathrm{NaOH}$ solution concentration increased at all ages. In addition, when the $\mathrm{NaOH}$ solution concentration was over $10 \mathrm{M}$, the compressive strength of the samples improved significantly.

(3) The compressive strength of the sample cured at $80^{\circ} \mathrm{C}$ for 24 hours presented a similar trend to that of the sample cured at $80^{\circ} \mathrm{C}$ continuously.

(4) The compressive strength of the sample cured at $25^{\circ} \mathrm{C}$ continuously improved significantly between 7 days and 28 days, even though the compressive strength of the sample showed the lowest value at 7 days.

(5) A higher proportion of unreacted fly ash spheres remained in the sample with low $\mathrm{NaOH}$ concentration (5M). In addition, some pores on the surface of the $5 \mathrm{M} \mathrm{NaOH}$ sample were observed.

(6) The sample that was obtained when the fly ash and stone powder sludge were activated with solutions of alkali hydroxide mixed with sodium silicate did not contain any crystalline phases except the ones existing in the fly ash and stone powder sludge.

\section{ACKNOWLEDGEMENT}

The author would like to graciously thank the Department of Civil and Environmental Engineering at the University of California, Berkeley for using the SEM/EDS and XRD analysis, in particular, Professor Paulo J. M. Monteiro, Dr. J. E. Oh and S. S. Jun of Construction Materials Group.

\section{REFERENCES}

Alonso S., and Palomo A. (2001) "Calorimetric study of alkaline activation of calcium hydroxide-metakaolin solid mixtures." Cement and Concrete Research, 31: 25-30

Carroll D. et al. (1998) "U.S. Portland cement industry, concrete and global climate." Proceedings of the 1998 $91^{\text {st }}$ Annual Meeting and Exhibition, 9

Choi S.J., Jeong Y., Kang W.S., Park C.S., Lee S.Y., Yeo B.C., and Lee S.S. (2006) "Influence of W/B ratio and replacement ratio of crushed sand on the fluidity and compressive strength of high strength concrete." Proceedings of $8^{\text {th }}$ Jap./Kor. Joint symposium on Building Materials \& Construction, 8: 153-158

Davidovits J. (1988) "Soft Mineralurgy and Geopolymer." In proceeding of Geopolymer 88 International Conference, the Université de Technologie, Compiène, France

Davidovits J. (1989) "Geopolymers: Inorganic Polymeric New Materials." J of thermal analysis, 37: 1633

Davidovits J. (1999) "Chemistry of geopolymer systems, terminology." In proceedings of Geopolymer '99 International Conference, France

Duxson P., Fernández-Jiménez A., Provis J.L., Lukey G.C., Palomo A., and van Deventer J.S.J. (2007) "Geopolymer technology: the current state of the art." J of Mater Sci, 42: 2917-2933

Fernández-Jiménez A., Garcia-Lodeiro I., and Palomo A. (2007) "Durability of alkali-activated fly ash cementitious materials." J of Mater Sci, 42: 3055-3065 
Fernández-Jiménez A., Palomo J.G. and Puertas F. (1999) "Alkali-activated slag mortars; Mechanical strength behavior." Cement and Concrete Research, 29: 13131321

Gartner E. (2004) "Industrially interesting approaches to "low- $\mathrm{CO}_{2}$ " cements." Cement and Concrete Research, 34: 1489-1498

Han C.G., Shin B.C., Kim G.C. and Lee S.T. (2001) "Strength and absorption properties of cement mortar produced with various content of sludge powder at mines, $J$ of the Korea Concrete Institute, 13, 561-567

Kim J.M., Jeong J.Y., Kim B.J. and Choi S.J. (2006) “The density and strength properties of lightweight foamed concrete using stone powder sludge in hydrothermal reaction condition." J of the Korea Concrete Institute, 18: 687-693

Kong D., Sanjayan J. and Sagoe-Crentsil K. (2006) "The behaviour of Geopolymer paste and concrete at elevated temperatures." International Conference on Pozzolan, concrete and Geopolymer, Thiland, 105-119

Sofi M. et al. (2007) "Bond performance of reinforcing bars in inorganic polymer concrete (IPC)." $J$ of Material Science, 42: 3107-3116

Takayuki F. and Masaru Y. (2002) "Applicability of crush stone powder and recycled concrete powder to high fluidity concrete." J of society of materials science, 51: 1105-1110

Wang S.D., Karen L. Scrivener and Pratt P.L. (1994) "Factors affecting the strength of alkali-activated slag." Cement and Concrete Research, 24: 133-1043

Xu A. In. Chandra S (ed) (1997) Waste materials used in concrete manufacturing, Noyes Publications, 141-173

(Date of Submission : 2010.3.3) 